\title{
ROMARIAS COMO MECANISMO DE LUTA PELA TERRA ${ }^{1}$
}

\author{
PILGRIMAGES AS MECHANISM OF FIGHT FOR LAND
}

Edimilson Rodrigues de Souza ${ }^{2}$

\begin{abstract}
RESUMO: A proposta deste artigo é problematizar alguns elementos advindos do trabalho de campo realizado no centro-norte do estado do Tocantins, com ênfase nas narrativas sobre conflitos de terra na região do Bico do Papagaio, especialmente na década de 1980, período no qual há uma atuação acentuada de agentes ligados aos setores progressistas da igreja Católica, notadamente Comissão Pastoral da Terra (CPT). Trata-se de uma aproximação inicial e análise de alguns dados da pesquisa em andamento sobre a ritualização de lideranças populares, violentamente assassinadas em áreas de intenso conflito fundiário, no Brasil, e processualmente transformadas em mártires da terra.
\end{abstract}

PALAVRAS-CHAVE: Mártires; Luta pela Terra; Romarias.

ABSTRACT: The proposal of this article is to problematize some elements derived from the field work carried out in the central north of Tocantins State, with emphasis on the narratives about land conflicts in the Bico do Papagaio region, especially in the 1980s, during which there is an action emphasized by agents linked to the progressive sectors of the Catholic Church, notably the Pastoral Commission of Land (CPT). It is an initial approximation and analysis of some data from the ongoing research on the ritualization of popular leaderships, violently murdered in areas of intense land conflicts in Brazil, and transformed into martyrs of the land.

KEYWORDS: Martyrs; Land conflicts; Pilgrimages.

\section{Introdução}

A região conhecida como Bico do Papagaio está localizada no extremo norte do estado do Tocantins, na zona de confluência dos estados do Pará, Maranhão e Tocantins, e é composta atualmente por 25 municípios: Aguiarnópolis, Ananás, Angico, Araguatins, Augustinópolis, Axixá do Tocantins, Buriti do Tocantins, Cachoeirinha, Carrasco Bonito, Darcinópolis, Esperantina, Itaguatins, Luzinópolis, Maurilândia do Tocantins, Nazaré, Palmeiras do Tocantins, Praia Norte, Riachinho, Sampaio, Santa Terezinha do Tocantins, São Bento do Tocantins, São Miguel do Tocantins, São Sebastião do Tocantins, Sítio Novo do

\footnotetext{
${ }^{1}$ A pesquisa que originou este texto é financiada pela Fundação de Amparo à Pesquisa do Estado de São Paulo (FAPESP), processo $n^{\circ}$ 2015/20035-9. As opiniões, hipóteses e conclusões ou recomendações expressas neste material são de responsabilidade do autor e não necessariamente refletem a visão da FAPESP.

2 Doutorando em Antropologia Social pela Universidade Estadual de Campinas (PPGAS-UNICAMP). e-mail: edimilsonrondon@gmail.com.
} 
Tocantins e Tocantinópolis. Esta área pertencia ao estado de Goiás e passou a compor o estado do Tocantins, criado em 1988, com a promulgação da nova Constituição brasileira. As referências ao longo do texto tomarão por base a data da criação do Tocantins.

A proposta deste artigo é problematizar alguns elementos advindos do trabalho de campo realizado no primeiro semestre de 2016, no centro-norte do estado do Tocantins, com ênfase nas narrativas sobre conflitos de terra na região do Bico do Papagaio, especialmente na década de 1980, período no qual há uma atuação acentuada de agentes ligados aos setores progressistas da igreja Católica, notadamente Comissão Pastoral da Terra (CPT). Trata-se de uma aproximação inicial e análise de alguns dados da pesquisa em andamento sobre a ritualização de lideranças populares, violentamente assassinadas em áreas de intenso conflito fundiário, no Brasil, e processualmente transformadas em mártires da terra.

O trabalho etnográfico desenvolvido nesta região concentrou-se na trajetória dessas lideranças (religiosas, sindicais, camponesas e indígenas). Muitos desses líderes foram assassinados, porque desenvolviam trabalhos de mobilização pelo direito à permanência e retomada ou posse de terras junto a grupos de posseiros. Sua atuação nestas zonas de conflito, sobretudo de enfrentamento e resistência junto a latifundiários e ao próprio estado brasileiro, provocou inúmeras ameaças, expropriações e assassinatos violentos (encomendados por grupos de fazendeiros e executado por pistoleiros, i.e., matadores de aluguel).

Em decorrência desses assassinatos e das sucessivas denúncias de violação de direitos fundamentais, por parte de organismos religiosos (especialmente setores progressistas da igreja Católica ligados à Teologia da Libertação) e entidades de direitos humanos (nacionais e internacionais), a luta protagonizada por estes líderes assassinados ganhou visibilidade nacional e internacional, sobretudo após sua morte.

Em razão das suas trajetórias de luta pela terra e pela vida, eles foram processualmente martirizados e transformados em modelos de ação, na medida em que sua biografia de resistência orienta novas estratégias de grupos e movimentos sociais na luta pela terra, água, floresta, entre outros recursos socionaturais.

O sentido de modelo de ação ganha clareza quando relaciona os atos de enfrentamento mobilizados por estas lideranças, que provocaram seus assassinatos e processual martirização, aos contextos de luta e de violência nos quais estavam imersos. Aqui é possível estabelecer um diálogo com a teoria do ritual elaborada por Stanley Tambiah, para este autor, 
multiple media, whose context and arrangements are characterized in varying degree by formality (conventionality), stereotypy (rigidity), condensation (fusion), and redundancy (repetition). Ritual action in its constitutive features is performative in these three senses: in the Austinian sense of performative wherein saying something is also doing something as a conventional act; in the quite different sense of a staged performance that uses multiple media by which the participants experience the event intensively; and in the third sense of indexical values - I derive this concept from Peirce - being attached to and inferred by actors during the performance (1985, $\mathrm{p}$. 128).

É importante frisar que os enfrentamentos relacionados aos conflitos fundiários nessas áreas ganharam força e visibilidade política com a emergência de ideais progressistas no interior da igreja Católica, a Teologia da Libertação (LENS, 1992; MAUÉS, 2010; PEREIRA, 2015).

A conformação de episódios de violência e condição de sujeição destes atores frente aos organismos do estado ${ }^{3}$ e elites locais, os históricos de migração em busca de terra para viver, e a perspectiva religiosa que orienta movimentos sociorreligiosos (QUEIROZ, 1976; MARTINS, 1980; 2009; VIEIRA, 2001), assim como pela presença de agentes mediadores ligados à igreja católica - Comunidades Eclesiais de Base (CEBs), Movimento de Educação de Base (MEB), Comissão Pastoral da Terra (CPT) e Conselho Indigenista Missionário (CIMI) - conformam as possíveis conexões entre estes contextos aparentemente diversos e dispersos.

\section{Contextos de luta pela terra e pela vida}

Para entender sumariamente o contexto histórico do qual emergem as questões que mobilizam esta pesquisa, vale explicar que a Amazônia brasileira tem vivenciado processos de colonização potencializados na segunda metade do século XX com a abertura das rodovias Belém-Brasília, Cuiabá-Santarém, Perimetral Norte e Transamazônica, o que provocou intensos fluxos migratórios para a região. Estas rodovias compunham o Plano de Integração Nacional (PIN) e mobilizaram grupos de camponeses, especialmente entre as décadas de 1960 e 1970. Uma das metas estabelecida no PIN era integralizar a Amazônia às demais regiões do país, estimulando a migração de colonos para a região. O êxito do projeto significava a solução dos problemas de "homens sem terra" nas regiões Nordeste, Sudeste e Sul do país, ocupando "terra sem homens" na Amazônia. A propaganda de integralização regional tinha como base "a situação insustentável de milhares de agricultores pressionados

\footnotetext{
${ }^{3}$ Dentre os quais destaco: Instituto Nacional de Colonização e Reforma Agrária (INCRA), Grupo Executivo de Terras do Araguaia-Tocantins (GETAT) e Superintendência do Desenvolvimento da Amazônia (SUDAM).
} 
pela crescente concentração da terra nas regiões de mais denso povoamento, como Nordeste, Paraná, Espírito Santo" (HÉBETTE, 2004, vol. I, p. 333). Contudo, ao estruturar essa política de "integralização", os órgãos governamentais desconsideraram a ocorrência de diversos fluxos migratórios anteriores, de populações camponesas, assim como a existência de povos indígenas de variadas etnias, conforme descreve Jean Hébette (2004).

Vale ressaltar que parte dessa política envolvia o incentivo e implantação de empreendimentos econômicos na Amazônia legal ${ }^{4}$, que entre as décadas de 1960 e 1980 provocou crescimento demográfico significativo nesta região, ocasionado pela abertura de grandes rodovias estaduais e federais, além da concessão de títulos de terras e incentivos fiscais a empresas privadas, seja para projetos de colonização dirigida ou para estímulo ao aumento da produção agropecuária. Este modelo político-econômico de ocupação humana foi uma das principais estratégias políticas, coordenada no âmbito do Projeto de Integração e Segurança Nacional, do Governo Federal, e provocou movimentos migratórios expressivos e diversos: de sitiantes do centro-sul do país, retirantes nordestinos, trabalhadores isolados oriundo do Maranhão e do Piauí, além de fazendeiros, grandes empresas nacionais e internacionais e grileiros ${ }^{5}$, principalmente.

Latifúndios e projetos de colonização foram implantados a partir de 1966 com incentivos fiscais e concessões de grandes áreas de terra pelo Governo Federal, através da recém-criada Superintendência do Desenvolvimento da Amazônia (SUDAM), que estimulava o crescimento demográfico e a concentração de latifúndios com o objetivo de aumentar a produção agropecuária na Amazônia Legal. Os conflitos fundiários nessas áreas têm como uma das suas principais matrizes essa política contraditória de colonização e de modernização conservadora.

\footnotetext{
${ }^{4} \mathrm{O}$ estado do Tocantins é um dos nove estados que compõem a Amazônia Legal brasileira, juntamente com os estados do Acre, Amapá, Amazonas, Pará, Rondônia, Roraima, Mato Grosso e Maranhão. Trata-se da subdivisão político-administrativa do Governo Federal, uma vez que ela abrange parte da região Centro-Oeste e Nordeste do Brasil (Mato Grosso e Maranhão, respectivamente) e não se orienta apenas pelas características do bioma amazônico, que abrange outros sete países da América do Sul, além do Brasil: Bolívia, Peru, Equador, Colômbia, Venezuela, Republica da Guiana, Suriname e Guiana Francesa. Com uma área de aproximadamente $5.217 .423 \mathrm{~km}^{2}$, de acordo com dados da Superintendência do Desenvolvimento da Amazônia (SUDAM), esta subdivisão foi instituída através da Lei $\mathrm{n}^{\circ}$. 1.806/1953, pelo presidente da República Getúlio Vargas, que criava a Superintendência do Plano de Valorização Econômica da Amazônia (SPVEA), transformada em SUDAM, pela Lei $n^{\circ}$. 5.176/1966, sancionada pelo então presidente Castelo Branco.

5 A grilagem consiste na falsificação de documentos de terra, que são artificialmente envelhecidos. Estes documentos são armazenados em contato com grilos, a urina e as fezes deste animal amarelam e mancham o papel. De acordo com Airton dos Reis Pereira (2015), é recorrente também a "falsificação de títulos de propriedade e seus registros, bem como de registro de escritura de compra e venda sem a linhagem da transmissão, normalmente com a conivência de serventuários de Cartórios de Registro Imobiliário e de órgãos governamentais. Em conjunto com esses procedimentos o grileiro usa da violência para expulsar e assassinar, normalmente trabalhadores rurais, seus concorrentes" (pp. 99-100).
} 
Esses acontecimentos produziram inúmeras formas de violência, invasões, e também negociações e barganhas entre índios e não índios ou mesmo entre diferentes povos indígenas como demonstraram DaMatta e Laraia (1978); Ianni (1978); Lima Filho (2001) e Martins (2009). A eclosão desses conflitos evidencia-se especialmente a partir da ocupação de terras devolutas, ou seja, propriedades públicas sem titularidade e por isso legalmente pertencentes ao estado, e da concessão dessas terras a grandes empresas agropecuárias pelos órgãos estatais.

O estímulo à migração dada pelo PIN que se justificava com a pretensão da resolução de conflitos fundiários, especialmente no Nordeste e Sudeste do Brasil, resultou na geração de novos conflitos pelos mesmos dilemas, a posse da terra. Descentralizando o problema, não se imaginou que pudessem ser organizadas novas formas de ocupação e resistência, em outros espaços de disputa. A confluência desses atores e a diversidade dos seus interesses tensionou a eminência de confrontos carregados de violência física e simbólica, seguida por expropriações e mortes.

Com esta descrição sumária dos conflitos na zona de confluência dos estados do Pará, Maranhão e Tocantins - o Bico do Papagaio -, pretendo avançar na descrição dos conflitos latentes nestas zonas, que provocaram a morte violenta de inúmeras lideranças populares. Algumas delas, não todas, foram eleitas à modelo de ação, e ritualizadas processualmente como mártires da terra, por setores progressistas da igreja Católica.

Se enquanto vivos sua atuação junto a grupos camponeses e indígenas era intensa, depois de mortos sua presença é frequentemente acionada em reuniões políticas e religiosas seja em eventos ordinários como encontros nos Sindicatos dos Trabalhadores Rurais (STRs), nas explicações das leituras bíblicas durante missas ou reuniões religiosas e conversas informais entre amigos ou em eventos extraordinários como romarias ou manifestações públicas. Em todos esses casos pude perceber que a agência desses mártires parece estar fundamentada em habilidades individuais, reconhecidas e legitimadas no interior do próprio grupo, tanto pelas trajetórias de luta e resistência quanto pelo seu percurso de formação por religiosos e missionários católicos ligados à Teologia da Libertação.

Matias Martinho Lenz, ao analisar a Teologia da Libertação, explica que este movimento se caracteriza por uma prática cristã libertadora "não só escatológica, mas buscada na história; de uma libertação simultaneamente na instância econômica, política e religiosa, entendidas como totalidade" (1992, p.125).

Para o autor, esta concepção teológica formulada após o Concílio Vaticano II (na primeira metade da década de 1960) "tenta traduzir para o campo religioso as críticas aos 
sistemas [econômico, político e religioso] levantadas pela análise social” (...). Dela emergem organizações pastorais militantes que trabalham junto a grupos marginalizados socialmente, caracterizadas pela conotação social e política das práticas religiosas (ibid.).

Entre suas principais ações destaca-se: "uma importante releitura de conceitos, concepções teológicas e textos religiosos, inclusive a Bíblia, lida agora por Comunidades Eclesiais de Base à luz de sua prática libertadora e como inspiradora da opção preferencial e 'evangélica' pelos pobres" (ibid.).

A realização de romarias da terra com o objetivo de homenagear, rememorar e ritualizar estes líderes mortos e martirizados parece funcionar como um operador da luta pela terra e pela vida nesta e em outras regiões do Brasil como vem demonstrando alguns autores (CHAVES, 2000; COMERFORD, 1999; 2003; LOERA, 2006; 2013). Estudos anteriores sobre romarias e peregrinações já demonstraram o caráter polissêmico deste tipo de ritual. Os trabalhos organizados por Simon Coleman e John Eade (2004), por exemplo, atentam para a ideia de continuidade sociocultural entre o local de origem dos peregrinos e o local de destino das peregrinações e romarias, ainda que não haja deslocamento espacial por longas distâncias, e reforçam o caráter afetivo e simbólico das peregrinações, como ato vivido pelo peregrino. Para estes autores a peregrinação não pode ser explicada apenas pelo seu caráter de liminaridade ou communitas $^{6}$ como sugeriu Turner (2008) e Turner e Turner (2011), pois nela estão presentes diversos atores que transitam do universo sagrado ao profano e não ocorrem rompimentos entre estruturas sociais ou criação de novas estruturas temporais, o que se evidencia são movimentos contínuos entre o local de origem dos peregrinos e o local de destino (de chegada da peregrinação).

Assim, os símbolos rituais deixam de ser vistos como forma transitória entre uma estrutura e outra e passam a ser analisados como contínuos e multissituados. As peregrinações, nestes termos podem ser tomadas como atos tanto religiosos quanto políticos ou como culturas em movimento.

\section{A trajetória do Padre Josimo na região do Bico do Papagaio-TO}

\footnotetext{
${ }^{6}$ As antiestruturas ou communitas são definidas como lugar liminar onde se estabelecem relações entre indivíduos concretos, de forma direta e imediata, enquanto a estrutura organiza-se no plano da obrigação institucionalizada (Turner 2008; 2013; Turner e Turner 2011).
} 
O trabalho de campo no Tocantins foi realizado entre abril e maio de 2016, neste período conheci pessoas que conviveram com o Padre Josimo Morais Tavares na década de 1980: ativistas políticos, lideranças sindicais, agentes de pastoral e religiosos.

Percorri boa parte da região centro-norte do estado do Tocantins, passando pelas cidades de Araguaína, sede do escritório da Comissão Pastoral da Terra (CPT) regional Araguaia-Tocantins; Campos Lindos, onde acompanhei os trabalhos da equipe de agentes da CPT, junto a agricultores familiares, atingidos pelos grandes projetos de monocultura de soja; Augustinópolis, Buriti do Tocantins, Esperantina e São Sebastião do Tocantins, localizadas na microrregião do Bico do Papagaio, extremo norte do Estado, para conhecer os locais onde Padre Josimo atuou como pároco e coordenador da CPT e contatar pessoas que conviveram com ele naquele período.

Na região do Bico do Papagaio conheci Irenir, agente pastoral da CPT, Maria Senhora, presidente da associação da Escola Família Agrícola (EFA) Padre Josimo, e Padre Edno, pároco nos municípios Buriti do Tocantins, São Sebastião do Tocantins, Carrasco Bonito e Esperantina. Josimo foi pároco nestas localidades, onde realizou trabalhos pastorais de formação religiosa e sindical entre os anos de 1983 e 1986, e coordenou a equipe da CPT.

O que passo a descrever abaixo sobre os trabalhos pastorais, assassinato e martírio do Padre Josimo é resultado do meu encontro com essas pessoas e das observações sistemáticas dos eventos que integraram a Semana Social da Terra e das Águas Padre Josimo, que em 2016 rememorou os 30 anos do assassinato dele, ocorrido em 10 de maio de 1986. Os acontecimentos que provocaram este assassinato serão explorados adiante.

Padre Josimo Morais Tavares atuava como agente da Comissão Pastoral da Terra, na região do Bico do Papagaio desde 1983. Nestas áreas além das atividades de pároco (celebração de missas e administração de sacramentos) ele também desenvolveu trabalhos pastorais junto a posseiros, pequenos agricultores e quebradeiras de coco babaçu. Sua atuação na formação de lideranças e de Comunidades Eclesiais de Base (CEBs) incomodou fazendeiros e grileiros da região, que não se conformavam com a atuação da igreja, protagonizada por Josimo, juntamente com as religiosas Nicole, Lourdes, Madeleine e Béatrice.

O religioso nasceu em 1953 em Marabá-PA, era filho único. Em 1957 sua família mudou-se da cidade de Marabá para Xambioá-GO, neste mesmo ano, depois de uma grande enchente. Aos 11 anos, Josimo ingressou no seminário menor Leão XIII, em TocantinópolisGO. Sua ordenação sacerdotal aconteceu em janeiro de 1979, na cidade onde ele cresceu, Xambioá-GO. Ele foi então enviado para assumir a paróquia de Wanderlândia-GO, cidade 
localizada também na região do Bico do Papagaio. Por ser filho único, quando foi ordenado padre Josimo levou sua mãe para morar consigo na paróquia em Wanderlândia e depois para São Sebastião do Tocantins.

Padre Josimo era coordenador da Comissão Pastoral da Terra da diocese de Tocantinópolis-GO, em 1983 foi transferido para a cidade de São Sebastião do Tocantins-GO, para auxiliar as religiosas Nicole, Lourdes, Madeleine e Béatrice, que já residiam na localidade. A transferência do padre foi motivada principalmente pela eclosão de conflitos pela terra nesta área.

Como pároco, Josimo atendia uma área de aproximadamente $100 \mathrm{~km}$, entre São Sebastião do Tocantins e Augustinópolis, celebrando missas, administrando sacramentos e realizando trabalhos pastorais via Comissão Pastoral da Terra: formação bíblica e sindical, por exemplo. A CPT naquele período pertencia à regional de Conceição do Araguaia, sul do Pará.

Desde então a equipe da CPT passou a ser composta pelas quatro religiosas, coordenadas por Josimo. A ação da CPT além da formação de camponeses também atentava para prisões e processos penais, aos quais eram submetidos os camponeses e posseiros destas áreas, em enfrentamento com os latifundiários, e pressionados pelas forças repressivas do regime civil-militar, que atingiram inclusive populações camponesas, vitimas de prisões e tortura, entre outras formas de violência (PEREIRA, 2015). As irmãs Madeleine e Béatrice lembraram que neste período, início da década de 1980, padre Josimo percorria toda aquela região, de São Sebastião até Sampaio, Carrasco Bonito, Buriti, Vila União, Centro dos Mulatos e Esperantina, celebrando missas e realizando reuniões de formação de lideranças, pastoral e sindical:

Então como o Josimo andava, conhecia todo o povo lavrador, os ajudava a tomar consciência dos direitos deles, a organizar sindicato, a organizar também comunidade de base, a organizar o que ter, porque 1980, 1981, foi a criação do PT [Partido dos Trabalhadores]. Lula veio, tem foto dele em Imperatriz, em São Miguel, então aquilo, o povo estava entusiasmado. Então o nosso trabalho junto com o Josimo e os outros era ajudar o povo nessas organizações. E as organizações foram crescendo e então os fazendeiros se sentiram acuados, por isso que eles tomaram essa decisão de matar o Josimo. E o Josimo pensava que não era possível, tinha muita fé, o corpo dele também era fechado, dizia: "não, padre, eles vão pensar duas vezes", só que aquele que matou o Josimo, qual o nome dele? O pistoleiro. Eles falaram para ele: "ele não é padre, ele é comunista", o que era ser comunista naquele tempo? Então porque um padre negro também, o povo não tinha muitos conhecimentos (Irmãs Marie Madeleine Hausser e Béatrice Kruch, entrevista concedida em 01/05/2017, no Assentamento Lagoa da Onça, Formoso do Araguaia-TO). 
Naquele momento ainda havia um receio do Governo Federal de que a formação sindical pudesse eclodir em movimentos similares à guerrilha do Araguaia ${ }^{7}$. Josimo chegou a ser preso, juntamente com a religiosa Lourdes e um lavrador, sob acusações diversas, inclusive de assassinar fazendeiros e organizar emboscadas no Bico do Papagaio.

\begin{abstract}
Madeleine: Prenderam [o padre] para amedrontar o povo e dizer "aqui que não vai ter nada". Espalharam os boatos.

Béatrice: E acusando Josimo e Lurdinha de ser o mandante da morte daquele fazendeiro. Eles prenderam também o lavrador, o lavrador ficou preso um bocado de tempo. Depois ficaram 5 ou 6 dias presos e soltaram eles. Isso foi em 1984. Em 1986 ele foi morto, em maio. A manifestação das quebradeiras de coco foi em 1985, fizemos manifestação com as mulheres quebradeiras de coco, tinha toda aquela problemática [impedimento de coletar coco babaçu nas fazendas]. Foi uma época muito movimentada (Irmãs Marie Madeleine Hausser e Béatrice Kruch, entrevista concedida em 01/05/2017, no Assentamento Lagoa da Onça, Formoso do AraguaiaTO).
\end{abstract}

Irenir e Dona Maria Senhora contam que Josimo era muito inteligente e fraterno, sempre dizia aos camponeses, especialmente às mulheres, quebradeiras de coco babaçu "estas terras do Bico [do Papagaio] são de todos vocês e que um dia produzirão leite e mel”. Esta afirmação é uma referência clara à saída do povo judeu das terras do Egito conduzidos pelo profeta bíblico Moisés até a terra de Canaã. Esta caminhada foi motivada pela promessa de que encontrariam uma terra fértil e abundante para viver, onde haveria leite e mel.

\begin{abstract}
Maria Senhora: Mandar o povo ocupar terra, ele nunca mandou, Josimo nunca mandou ninguém ocupar terra. Mas ele evangelizava, aí o povo descobriu "se essa terra é de Jesus, eu sou filho dele, eu que estou aqui, eu pago imposto nesse país, por que, que alguém tem terra e eu não tenho? Se a terra é de todo mundo".

"A terra é de todo mundo", isso que Josimo foi dizer, e foi no evangelho, ele não foi dizer "entra na terra do fulano", o pessoal que descobriu. Se tinha necessidade ou não de terra.

Irenir: Foi uma das vitórias depois de muito tempo, que a gente canta "vai pra uma terra onde jorra leite e mel". Aí oh, a terra produziu leite da vaquinha, os agricultor produziram mel, então chegamos a terra onde jorra leite e mel. E aqui no Bico teve apicultor, um bocado de gente que sabe mexer com abelha, que não dá nem tanto trabalho (Irenir Farias e Maria Senhora, entrevista concedida em 17/04/2016, em Esperantina-TO).
\end{abstract}

\footnotetext{
7 “A Guerrilha do Araguaia teria sido o confronto armado entre 69 militantes do PCdoB e o Exército na região do Araguaia, entre 1972 e 1975, na divisa dos Estados de Goiás e Pará. Com o objetivo de derrubar o governo da ditadura militar e instaurar no País uma 'democracia popular' militantes do PCdoB passaram a viver clandestinamente entre posseiros da região. Descobertos pelo Exército, iniciou-se, em abril de 1972, uma guerra de guerrilhas terminando somente em janeiro de 1975 após a morte de quase todos os militantes do partido" (PEREIRA, 2004, p. 50).
} 
Enquanto me contavam esta história, Irenir se lembrou do refrão de uma música cantada naquele período nas reuniões das CEBs "para a terra prometida o povo de Deus marchou, Moisés andava na frente, hoje Moisés é a gente quando enfrenta o opressor”.

Atualmente os camponeses criam gado de leite e possuem criatórios de abelhas, sempre me diziam que a profecia do Josimo foi realizada, porque as terras do Bico do Papagaio produzem leite e mel.

As mobilizações de camponeses estimuladas pelo padre geraram um clima de insatisfação por parte dos fazendeiros da região. Irenir e Dona Maria explicam que ele passou a sofrer várias ameaças de morte, mas não se intimidou diante delas:

Maria Senhora: [...] aí depois começaram ameaçar matar ele, e a gente pelejava pra
ele, inclusive no dia que era, que mataram ele, aquele dia ele ia pra uma reunião de
brincadeirinha, que a ideia era chegar lá e fazer com que ele não voltasse pra cá. Essa
era a ideia dos leigos.
Irenir: Tirar ele daqui.
Maria Senhora: Tirar ele daqui.
Edimilson: Por que ele falava que não queria sair?
Maria Senhora: Não, ele não saia não, ele dizia: "se eu sair quem vai falar por
vocês?" e naquela época, se ele tivesse saído mesmo, tivesse ido embora, eu não sei
não, eu acho que nós não tínhamos resistido, porque não tinha outro padre na região
pra fazer o que ele fazia. Como foi a morte dele, aí a gente resistiu, porque todo
mundo se juntou naquela hora. [...] então, que eu acho que seria diferente se tivesse
ele tivesse indo embora, sem ter um padre que fizesse um testamento dele no
momento, mas com a morte dele o pessoal se revoltou e reagiu. Então assim, foi uma
convivência muito boa, que ele teve, ele deixou um legado muito grande, mas muito
grande, que foi o povo agricultor saber qual é o seu lugar, saber entrar e sair, do nosso
modo, e isso graças ao legado que o Padre Josimo deu. Não foi só pra mim não, foi
pra muita e muita gente no Bico [do Papagaio] e no estado. Todos tiveram uma
capacitação da igreja católica de cidadão, do seu modo, do seu jeito, em formar a
liderança (Irenir Farias e Maria Senhora, entrevista concedida em 17/04/2016, em
Esperantina-TO).

Além das ameaças de morte, ele sofreu uma tentativa de assassinato no dia 17 de abril de 1986, mas sobreviveu aos cinco tiros que foram disparados contra a Toyota que ele dirigia em Augustinópolis.

Menos de um mês depois ele se deslocou para a cidade de Imperatriz-MA, para uma reunião no escritório da CPT Araguaia-Tocantins. Era dia 10, sábado, véspera do dia das mães, explicou-me Irenir. Enquanto ele subia as escadas da Mitra Diocesana de ImperatrizMA, onde funcionava o escritório da CPT alguém o chamou "Josimo", quando ele se virou recebeu dois tiros, logo abaixo das costelas, na altura do peito. Chegou ao hospital com vida, mas não resistiu.

Madeleine: E nesse outro dia, que era para fazer o curso de bíblia, aí nós falamos [para o padre Josimo]: "você não vem, nós damos conta". Que quando nós vimos o 
carro sem ele, a primeira coisa foi "cadê o Josimo?" "Não, ele foi para Imperatriz", "gente, pelo amor de Deus, não fala isso", eu larguei o curso, a Bia ficou com o povo, eu fui lá em casa, ofereci um café, mas naquela agonia. Também não demoram muito, voltaram. Uma hora depois chega outro embaixador falando assim, "mataram o homem". Aí nós gelamos: "mataram o homem? Uai, quem é?". "O Josimo. Lá em Imperatriz. Ele subindo a escadaria do escritório de CPT, lá na Diocese de Imperatriz, tem um que baleou ele nas costas". "Meu Deus do céu!", a gente não tinha carro, aliás, naquele dia nós tínhamos o fusquinha das irmãs.

Béatrice: A Dona Olinda [mão do padre Josimo] e o menino não tinham chegado nem em Buriti quando receberam essa notícia.

Madeleine: No meio da estrada receberam a notícia. E nós, "meu Deus, quê que nós faz? Não é possível, não é possível”, aí sabe, foi uma agonia, agonia, agonia daquelas.

Béatrice: Aí, fomos logo para Buriti, a mãe já tinha ido, a dona Olinda não sei com quem.

Madeleine: A nossa valência é que nós estávamos com o fusquinha do CPT, que a Nicole tinha saído no dia primeiro de maio e deixou aquele carro, senão nós iríamos estar sem poder sair de lá. Aí, fomos direto para?

Béatrice: Tocantinópolis. Que a gente se informou em Buriti, "não, dona Olinda já foi”, porque senão nós teríamos levado ela e aí nós fomos direto para Tocantinópolis (Irmãs Marie Madeleine Hausser e Béatrice Kruch, entrevista concedida em 01/05/2017, no Assentamento Lagoa da Onça, Formoso do Araguaia-TO).

Este episódio lembrado com detalhes pelas religiosas e também por todas as pessoas que conviveram com o padre Josimo foi retratado num painel no altar da igreja Católica de Buriti do Tocantins-TO, pintado pelo padre claretiano Maximino Cerezo Barredo. Nesta igreja padre Josimo atuou como pároco, e o seu corpo foi sepultado no interior dela.

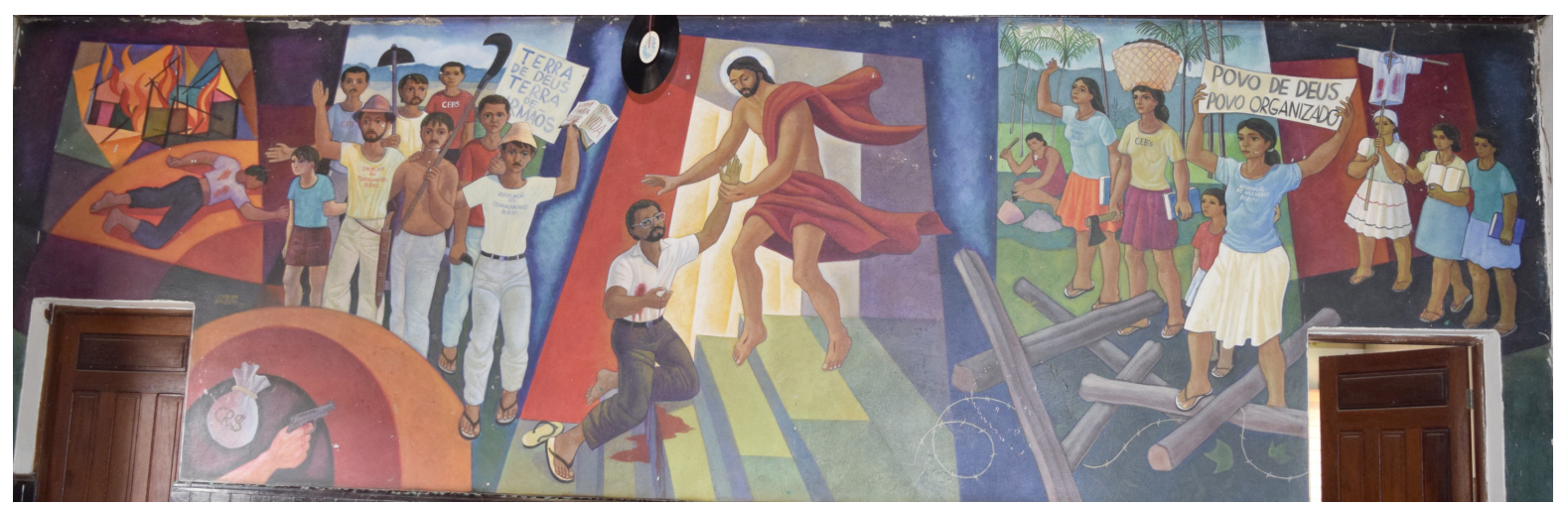

Imagem 01: Painel que retrata o assassinato de Padre Josimo. Foto do autor, 2016

No painel, Padre Josimo aparece baleado, nas escadas, calçado com chinelos, uma das características pelas quais ele é sempre lembrado e que faz referência à sua atitude simples e popular. Também são retratados Jesus Cristo segurando Padre Josimo por uma das mãos, um grupo de mulheres em procissão com a camisa de Padre Josimo ensanguentada, outro grupo de mulheres quebrando coco babaçu e um grupo de homens, trabalhadores rurais com enxada e foice. Há duas faixas com os escritos "terra de Deus, terra de irmãos" e "povo de Deus organizado", que fazem alusão ao trabalho da CEBs naquele período, na região. 
Sugiro isto a partir dos escritos pintados nas camisetas do grupo de homens à esquerda do painel, nas quais estão escritos: CPT, Sindicato dos Trabalhadores Rurais, Associação dos Trabalhadores Rurais e CEBs. E também pelos escritos nas camisetas do grupo de mulheres à direta: Comissão de Diretos Humanos Padre Josimo, CEBs e Associação de mulheres Buriti.

Pedro Tierra, em 1986 escreveu um poema sobre Padre Josimo, que também pode dialogar para entendermos os elementos deste painel:

Quem é esse menino negro/ Que desafia limites?/ Apenas um homem./ Sandálias surradas./ Paciência e indignação./ Riso alvo./ Mel noturno./ Sonho irrecusável./ Lutou contra cercas./ Todas as cercas./ As cercas do medo./ As cercas do ódio./ As cercas da terra./ As cercas da fome./ As cercas do corpo./ As cercas do latifúndio (p. 13).

Padre Josimo também era poeta e escritor, um dos seus escritos é o testamento espiritual, redigido pelo próprio padre, logo após a primeira tentativa de homicídio em abril de 1986, e lido durante a Assembleia Diocesana de Tocantinópolis-GO, dias antes de seu assassinato:

[...] Tenho que assumir. Agora estou empenhado na luta pela causa dos pobres
lavradores indefesos, povo oprimido nas garras dos latifúndios. Se eu me calar,
quem os defenderá? Quem lutará a seu favor? Eu pelo menos nada tenho a perder.
Não tenho mulher, filhos e nem riqueza sequer, ninguém chorará por mim. Só tenho
pena de uma pessoa: de minha mãe, que só tem a mim e mais ninguém por ela.
Pobre. Viúva. Mas vocês ficam aí e cuidarão dela. Nem o medo me detém. É hora de
assumir. Morro por uma justa causa. Agora quero que vocês entendam o seguinte:
tudo isso que está acontecendo é uma conseqüência lógica resultante do meu
trabalho na luta e defesa pelos pobres, em prol do Evangelho que me levou a
assumir até as últimas conseqüências.
A minha vida nada vale em vista da morte de tantos pais lavradores assassinados,
violentados e despejados de suas terras. Deixando mulheres e filhos abandonados,
sem carinho, sem pão e sem lar. É hora de se levantar e fazer a diferença! Morro por
uma causa justa [...] (fonte: arquivo da paróquia de São Sebastião do Tocantins,
disponibilizado pelo padre Edno).

Neste documento é possível reconhecer indícios, que possibilitam sugerir a conjunção entre religião e política. Tendo em mente que um dos objetivos deste trabalho é problematizar como caminhadas de cunho religioso, que rememoram mártires da terra, operam também, como os nossos dados vêm evidenciando, como ação política de enfrentamento e resistência, notadamente entre camponeses e indígenas, em percursos de luta pela terra e pela vida.

Outra questão que me parece relevante é a afirmação de Edmundo, coordenador da CPT Regional Araguaia-Tocantins, enquanto conversávamos em abril de 2016 sobre o assassinato do Padre Josimo: "estar pronto para morrer significa estar disposto a lutar até as 
últimas consequências. É diferente de querer morrer. Josimo não queria morrer, mas sabia que na luta pela terra estava implícito o risco do assassinato".

A Romaria da Terra e da Água Padre Josimo acontece em anos ímpares, sempre no mês de maio, no estado do Tocantins. Até 2015 esta peregrinação era itinerante, ou seja, a cada dois anos ela foi realizada em cidades diferentes, mas sempre na região norte do Tocantins, sobretudo nas cidades da área conhecida como Bico do Papagaio. A primeira romaria aconteceu em 1988. Em 2015 foi realizada a 14 a edição desta romaria em ColinasTO. A partir de 2016 decidiu-se que a Romaria da Terra e da Água Padre Josimo acontecerá sempre entre as cidades de Buriti do Tocantins e São Sebastião do Tocantins, por duas razões particulares: ele atuou como pároco e agente da CPT nestes dois municípios e seu corpo foi sepultado na igreja do Buriti do Tocantins.

Rafael, agente da CPT, me contou que em 2015 a romaria da terra e da água Padre Josimo reuniu aproximadamente 1000 romeiros e romeiras. Eram camponeses, indígenas (Apinayé e Xerente), quilombolas, religiosos, agentes de pastoral e lideranças de movimentos sociais.

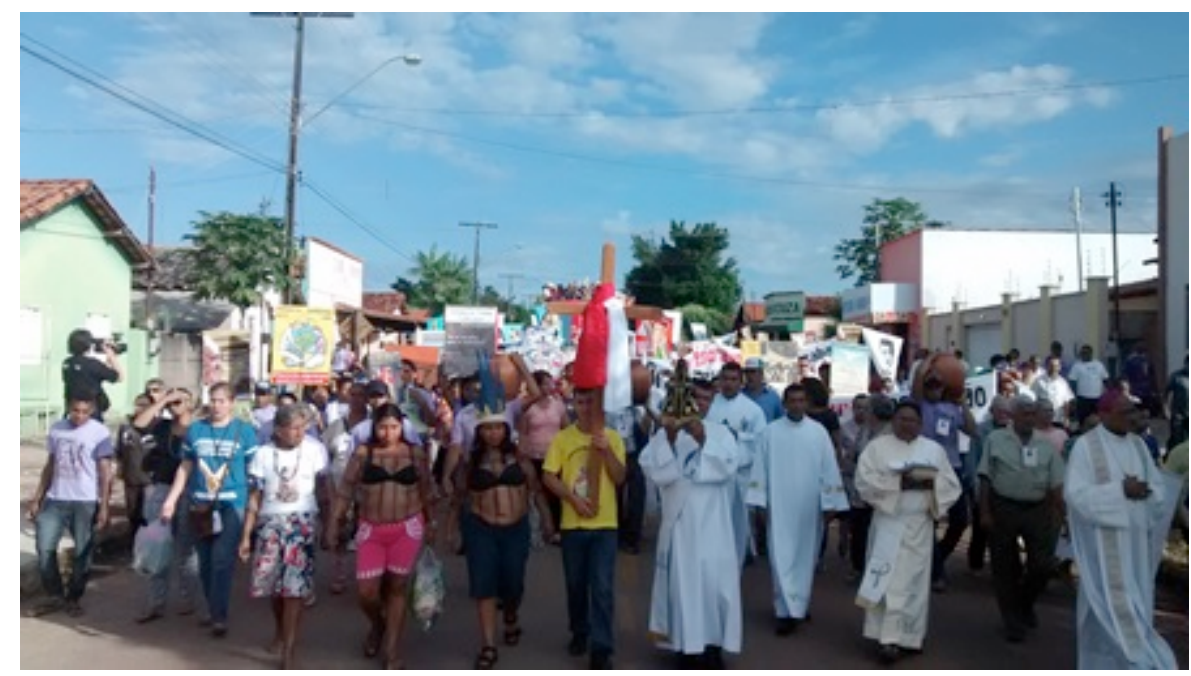

Imagem 02: 14ª Romaria da terra e da água Padre Josimo. Foto: Rafael Oliveira, 2015

Edmundo, coordenador da CPT Regional Araguaia-Tocantins, me explicou que as romarias da terra e das águas Padre Josimo são organizadas como mecanismo de rememorar a luta estimulada pelo padre e como forma de denúncia aos conflitos ainda latentes na região do Bico do Papagaio e em outras regiões do Tocantins. Entre os agentes da CPT é recorrente a expressão "a luta continua". 
A equipe da CPT relatou que Dom Geovane, bispo da diocese de TocantinópolisTO oficializou a romaria como prática pastoral, incluindo-a no calendário religioso, com periodicidade bianual. Por conta do trabalho desenvolvido pelo Padre Josimo nesta região e pelo volume de conflitos por terra ainda registrados nesta área, o padre foi eleito à mártir e padroeiro desta diocese.

Nesta direção, a romaria é o momento de reunir as lideranças da região e de rememorar o trabalho desenvolvido pelo Padre Josimo enquanto pároco e agente da CPT. Além de publicizar denúncias de violação de direitos humanos, expropriações e assassinato de lideranças sindicais, camponesas e indígenas.

\section{Considerações finais}

Alessandra Regina Santos (2014), em seu estudo sobre um grupo de remanescentes de quilombo no Vale do Ribeira, estado de São Paulo, mostra como aspectos da cosmologia dos habitantes de Pedro Cubas estão relacionados não apenas às suas práticas cotidianas, como relações de parentesco e cultivo, mas aparecem, por exemplo, nas relações estabelecidas entre este povo e os agentes do estado, assim como nas lutas políticas por demarcação e titulação do território.

Para esta autora, os conflitos decorrentes da regularização fundiária da Comunidade Remanescente de Quilombo de Pedro Cubas emergem da ineficiência dos agentes do estado - INCRA e ITESP (Fundação Instituto de Terras do Estado de São Paulo) em reconhecer lógicas distintas de percepção do espaço. No caso específico dos habitantes desta localidade, uma procissão conhecida como "Recomendação das Almas", marcada por cânticos, rezas e visitas ao cemitério na sexta-feira santa, período da quaresma - ocasião na qual o catolicismo celebra a paixão e morte de Jesus Cristo - compõe o acervo mnemônico desse grupo e revela os limites físicos do seu território ao evidenciar a relação entre o mundo dos vivos e dos mortos (ibid., pp. 10-11).

Nesta caminhada, as almas para as quais os moradores de Pedro Cubas oferecem cantos e orações são convidadas a caminhar junto a eles. Durante a procissão de Recomendação das Almas, visitam terreiros de algumas casas habitadas por vivos ou abandonadas - o que sugere estar habitada por almas de pessoas que já viveram ali -, encruzilhadas, trilhas abertas na mata e estradas de chão às margens do rio Ribeira de Iguape.

Na perspectiva de Santos (2014) esses deslocamentos pelo território até o antigo cemitério, no qual foram enterrados os antepassados desse povo, são reveladores das relações 
de alianças, parentesco e consaguinidade, que dão sentido ao tempo vivido e ao espaço habitado por eles: "A Recomendação das Almas permite-nos perceber como os antepassados conectam os habitantes de Pedro Cubas à terra, interpenetram sua paisagem. Uma conexão singular entre o mundo dos vivos e o mundo dos mortos é estabelecida ou reestabelecida" (ibid., pp. 20-21;31).

A partir da leitura deste contexto etnográfico, que relaciona mortos e território, é possível sugerir que não há em algumas cosmologias uma distinção rígida entre vida e morte, em vez disto evidencia-se permeabilidade e conectividade mútuas entre estes dois mundos, sobretudo em contextos sociais acentuados por fluxos de relações contínuas e atualizados por condições de vida marcadas por vulnerabilidade, expropriação, violência e morte.

O argumento de Ana Luísa Martins Micaelo sobre os camponeses do assentamento Arupema na Zona da Mata pernambucana (2014) também produz ecos interessantes para pensar a relação entre cosmologias e lutas pela posse da terra de grupos camponeses no Brasil. Micaelo demonstra que se por um lado os aspectos materiais da luta pela posse da terra aparecem no cultivo de árvores frutíferas - que indicam o tempo de ocupação e o trabalho investido na terra, entre outros marcadores de habitabilidade - por outro, o ato de "plantar" o umbigo da criança (placenta), assim que esta nasce, opera uma relação indissociável entre a criança e a terra, uma continuidade ontológica entre a pessoa e o seu destino, garante prosperidade financeira (quando enterrado na porteira de uma fazenda) e provoca seu retorno ao lugar de nascimento ainda que seja necessário em algum momento da vida se deslocar por necessidade financeira, expropriação ou expulsão (MICAELO, 2014, pp. 167-182).

Poderíamos nos perguntar o que há de comum entre quilombolas do Vale do Ribeira, camponeses da Zona da Mata pernambucana e romeiros do Bico do Papagaio. A resposta que me parece mais apropriada é: mesmo habitando em regiões tão diversas e distantes, esses atores sociais compartilham condições de vida muito semelhantes, marcadas por resistência em permanecer em suas terras e por episódios de violação de direitos, inclusive o direito à vida.

Nessa direção, os contextos e os atos que possibilitam a realização da Romaria da Terra e da Água Padre Josimo, a condição de vulnerabilidade, potencializada pelo assassinato de suas lideranças políticas, reforçam a luta dos presentes, unidos aos mártires antes e depois da morte, cujo sentido se inscreve e se fixa como resistência e continuidade. A celebração do martírio é um motivo para se encontrar, partilhar o sofrimento e reunir forças para continuar resistindo. 
Ao refazer o caminho dos mártires os romeiros transformam sistemas simbólicos, modificam o estatuto da vida e da morte, traduzida em violência e recolocam o líder morto e martirizado no centro da luta pela terra e pela vida.

Trata-se de operações no campo semântico. Evidentemente elementos presentes nas ontologias destes grupos são acionados, mas o operador principal são as traduções de morte violenta em martírio e os contextos a partir dos quais estas relações de violência e expropriação emergem ${ }^{8}$.

Os peregrinos, por sua vez trazem à tona a dimensão criativa e reivindicativa do ato, transformam os mártires em operadores das relações entre pessoas e mundos. $\mathrm{O}$ ato de caminhar, de rememorar lideranças assassinadas e transformadas processualmente em mártires produzem pessoas e relações, provocando a presença dos mártires que caminham junto aos romeiros. Não se trata de incorporação de espíritos, mas de disseminação de força e energia, em símbolo de luta.

\section{REFERÊNCIAS}

CHAVES, Christine Alencar. A Marcha Nacional dos Sem-Terra: Um Estudo sobre a Fabricação do Social. Rio de Janeiro: Relume Dumará, 2000.

COLEMAN, Simon; EADE, John (eds.). Reframing Pilgrimage. Cultures in motion. London e New York: Routledge, 2004.

COMERFORD, John Cunha. Fazendo a luta: sociabilidade, falas e rituais na construção de organizações camponesas. Rio de Janeiro: Relume Dumará, 1999.

. Como uma família: sociabilidade, territórios de parentesco e sindicalismo rural. Rio de Janeiro: Relume Dumará, 2003.

DAMATTA, Roberto; LARAIRA, Roque de Barros. Índios e Castanheiros: a empresa extrativa e os índios no Médio Tocantins. Rio de Janeiro: Paz e Terra, 1978.

HÉBETTE, Jean. Cruzando a Fronteira: 30 anos de estudo do campesinato na Amazônia. Vols. I, II, III e IV. Belém: EDUFPA, 2004.

IANNI, Otávio. A luta pela terra: história social da terra e da luta pela terra numa área da Amazônia. Rio de Janeiro: Vozes, 1978.

\footnotetext{
${ }^{8}$ Não seria possível chegar a estas conclusões sem o aporte dos argumentos de Cristiana Pompa (2003) sobre as relações estabelecidas entre missionários, colonizadores e povos indígenas no Brasil colonial, no entanto, reconheço as distinções entre o contexto etnográfico da autora e o universo social do qual emergem as transformações de lideranças violentamente assassinadas em mártires da terra.
} 
LENS, Matias Martinho. Festas religiosas, CEBs e mudanças. In: SANCHIS, Pierre (org.), Catolicismo. Unidade religiosa e pluralismo cultural. São Paulo, Loyola: 1992.

LIMA FILHO, Manuel Ferreira. O desencanto do oeste. Goiânia: UCG, 2001.

LOERA, Nashieli Rangel. A espiral das ocupações de terra. São Paulo: Polis, 2006. - Compromissos, dívidas e dons entre acampados, assentados, movimentos e Estado. In: PIETRAFESA DE GODOI, Emília; MENEZES, Marilda (orgs.). Uma terra para se viver: assentados, colonos e quilombolas. São Paulo, Annablume: 2013.

MARTINS, José de Souza. Expropriação e Violência: A Questão Política no Campo. São Paulo: Hucitec, 1980.

. Fronteira: a degradação do outro nos confins do humano. São Paulo: Hucitec, 2009.

MAUÉS, Raymundo Heraldo. Comunidades "no sentido social da evangelização": CEBs, camponeses e quilombolas na Amazônia Oriental brasileira. Religião e Sociedade. Rio de Janeiro, vol. 30(2), pp. 13-37. 2010.

MICAELO, Ana Luísa Martins. Essa terra que tomo de conta: parentesco e territorialidade na zona da mata de Pernambuco. 2014. 246p. Tese (Doutorado em Antropologia) - Curso de Pós-Graduação em Antropologia, Universidade de Lisboa. Lisboa-Portugal.

PEREIRA, Airton dos Reis. O papel dos mediadores nos conflitos pela posse da terra na região Araguaia paraense: O caso da fazenda Bela Vista. 2004. 224p. Dissertação (Mestrado em Extensão Rural) - Curso de Pós-Graduação em Extensão Rural, Universidade Federal de Viçosa. Viçosa.

. Do Posseiro ao sem-terra: A luta pela terra no sul e sudeste do Pará. Recife: Editora UFPE, 2015.

POMPA, Cristina. Religião como tradução: missionários, Tupi e Tapuia no Brasil Colonial. Bauru-SP: EDUSC, 2003.

QUEIROZ, Maria Isaura Pereira de. O messianismo no Brasil e no mundo. São Paulo: AlfaOmega, 1977.

SANTOS, Alessandra Regina. Nesse solo que vós estais, lembrai-vos que é de morrer: uma etnografia das práticas de caminhar, conhecer e mapear entre os habitantes de Pedro Cubas, um remanescente de Quilombo do Vale do Ribeira-SP. 2014. 125p. Dissertação (Mestrado em Antropologia Social) - Curso de Pós-Graduação em Antropologia Social, Universidade Federal de São Carlos. São Carlos.

TAMBIAH, Stanley Jeyaraja. Culture, Thought and Social Action. Cambridge: Harvard University Press, 1985. 
TIERRA, Pedro. A morte anunciada do Josimo Tavares. In: Pe. Josimo: a velha violência da nova república. Goiânia: CPT, 1986.

TURNER, Victor. Dramas, campos e metáforas: Ação simbólica na sociedade humana. Niterói-RJ: EdUFF, 2008.

; TURNER, Edith. Image and pilgrimage in Christian culture. New York: Columbia University Press, 2011.

VIEIRA, Maria Antonieta da Costa. À procura das Bandeiras Verdes: viagem, missão e romaria. Movimentos sócio-religiosos na Amazônia Oriental. 2001. 623p. Tese (Doutorado em Ciências Sociais) - Curso de Pós-Graduação em Ciências Sociais, Universidade Estadual de Campinas. Campinas. 